\title{
O processo de construção e desconstrução da tela de proteção social do trabalho: tempos de regresso
}

\author{
MAGDA BARROS BIAVASCHI ${ }^{I}$
}

Ociosa, mas alargada de preocupações sexuais, a vida do senhor de engenho tornou-se uma vida de rede. Rede parada, com o senhor descansando, dormindo, cochilando. Rede andando, com o senhor em viagem ou a passeio debaixo de tapetes ou cortinas. Rede rangendo, com o senhor copulando dentro dela. Da rede não precisava afastar-se o escravocrata para dar suas ordens aos negros...

(Gilberto Freyre, Casa grande \& senzala, 1987).

\section{Introdução}

$\int$ UNDAMENTADO em tese apresentada em novembro de 2005 ao Instituto de Economia da Unicamp para obtenção do titulo de doutor em Economia Social do Trabalho, publicada pela Editora LTr em 2007 (Biavaschi, 2007), bem como nos estudos em andamento no eixo “Terceirização" do Projeto Temático: "Contradições do Trabalho no Brasil Atual. Formalização, precariedade, terceirização e regulação”, Processo n.2012/20408-1, o artigo abre com epígrafe de Gilberto Freyre. O cenário é o da Casa grande de uma sociedade escravocrata, patriarcal e monocultora, na qual os direitos dos homens eram sonegados à grande maioria (Costa, 1999). Referências que contribuem para que se compreendam os desafios ainda hoje colocados à constituição de uma sociedade brasileira menos desigual e mais justa, com normas de proteção que possibilitem sejam concretizados os princípios da dignidade humana e do valor social do trabalho que a Constituição Federal de 1988 escreve como pilares da República.

Com o dinamismo da economia nucleado pela expansão da acumulação cafeeira, as grandes fazendas monocultoras faziam uso da mão de obra escrava. No final do século XIX, porém, o trabalho escravo já havia perdido importância. Em 1888, quando da Abolição, as novas oportunidades de trabalho aproveitavam-nas os imigrantes. A Lei Áurea introduziu a liberdade meramente negativa: a possibilidade de os negros saídos da escravidão irem embora para onde quisessem, sem qualquer mecanismo apto a lhes assegurar a condição de cidadãos, su- 
jeitos de direitos. Moldados em um sistema servil, muitos ficaram nas propriedades rurais como agregados. Outros, errantes, trabalhavam aqui e acolá. Outros tantos buscavam nas cidades oportunidades de vida, desenvolvendo, em regra, atividades das mais subalternas. Nesse processo, consolidava-se a exploração de mão de obra barata, em uma sociedade cujo tecido era costurado pelo signo da desigualdade e da exclusão (Barbosa de Oliveira; Henriques, 1990), dificuldades acirradas pelas políticas de imigração que Vargas, em 1930, buscou superar com a Lei dos Dois Terços.

A Abolição livrou o país de seus inconvenientes. Quanto aos negros, porém, abandonou-os à própria sorte. As dificuldades que tiveram de integração à sociedade eram atribuídas à inferioridade da raça. Marcas de uma herança herdada dos tempos do Brasil colônia que acabaram inscritas, a ferro e fogo, na estrutura social, econômica e política deste Brasil de mil e tantas misérias ${ }^{1}$ (Biavaschi, 2007). A relação entre escravo e senhor formalmente acabou por culminar no homem "livre", sem que fossem superadas as condições instituintes da dominação e da sujeição. ${ }^{2}$

Ainda hoje percebem-se resquícios dessa herança: seja na ausência de política eficaz de democratização do acesso a bens essenciais à dignidade humana, como terra, renda, saúde e emprego decente; seja nas dificuldades enfrentadas pelas trabalhadoras domésticas para serem incorporadas ao campo de abrangência da Consolidação das Leis do Trabalho (CLT), em árdua luta para aprovação da chamada "PEC das Domésticas" e, depois, para sua regulamentação; seja na exploração da força de trabalho em condição análoga à de escravo e nos obstáculos colocados ao processo de tramitação da PEC n.438/01 que autoriza expropriação da propriedade rural e urbana quando evidenciada exploração da força de trabalho nessas condições; seja no movimento regressivo expresso em projetos de lei em tramitação no Parlamento, como, entre outros, o PLC n.3/2015 que regula a terceirização, o que reduz a idade para o trabalho, o que flexibiliza o conceito de trabalho escravo, o que introduz a supremacia do negociado sobre o legislado; seja nas formas de preconceito e discriminação que se manifestam em diversos setores da sociedade e da política e que, volta e meia, tornam vivos os refrãos do Rappa:" "A carne mais barata no mercado / É a carne negra", e "Todo Camburão tem um pouco de Navio Negreiro", expressões de sadismo e masoquismo presentes na formação da sociedade brasileira (Biavaschi, 2007).

Freyre (1987) sabia que para superar o trauma da escravidão era preciso mergulhar no âmago da sociedade, desnudando-a em suas enfermidades que anulam o indivíduo. Uma sociedade centrada na vontade e no poder do senhor da Casa grande, que, completada pela senzala, representava um sistema econômico, social e político (Biavaschi, 2007). Daí a citação que abre este artigo, no qual é abordado o processo brasileiro de construção do arcabouço de proteção ao trabalho que, iniciado na década de 1930, completa-se com a Constituição de 1988 quando os ventos liberais já se faziam sentir no Brasil. 
O texto tem três momentos: o primeiro discute a gênese do Direito do Trabalho, localizando-a no século XIX, em tempos de capitalismo constituído, trazendo, a seguir, sucinta contextualização socioeconômica do Brasil de então para, a partir dela, abordar o processo de construção das normas de proteção ao trabalho, com ênfase à Justiça do Trabalho e à CLT. O segundo aborda o processo de desconstrução dessa tela de proteção, com foco na terceirização. $\mathrm{O}$ último momento contempla as considerações finais.

\section{Primeiro momento}

No século XIX, em tempos de laissez-faire e de capitalismo constituído, uma nova forma de uso da mão de obra se fazia prevalente: os trabalhadores vendiam sua força de trabalho a outrem, de forma subordinada e assalariada. À medida que esse novo modo de produção se desenvolvia, o trabalho, de concreto, transformava-se em abstrato; o valor de uso passava a ser, também, portador do valor de troca. Na Grande indústria, a força de trabalho era vendida aos proprietários dos bens de produção que, personificando o capital, compravam-na pelo valor diário e a consumiam durante o tempo trabalhado. Assim, a força de trabalho passou a ser vista como fator de produção. O trabalho, que exterioriza a personalidade do ser humano, virou coisa. O trabalhador, dominado pelo trabalho morto objetivado nos meios de produção, viu-se destituído até de seu saber técnico, detido agora pelo capital no domínio do processo de valorização que o submete (Marx, 1977). E ao invés da prometida sociedade de homens iguais, livres e fraternos, acirravam-se as desigualdades e as iniquidades (Biavaschi, 2007; 2016).

Mas, se, por um lado, a exploração da força de trabalho era intensificada, por outro, se foi conformando uma classe operária homogênea e um mercado de trabalho unificado (Barbosa de Oliveira, 2003, p.63) que a Grande indústria passou a regular. Ainda que a palavra fosse trabalhar até morrer, sem limites, ao redor das máquinas os trabalhadores se uniam, seguindo-se uma luta mais organizada do que outra, visando a manter salários, reduzir jornadas, melhorar as condições de trabalho (Biavaschi, 2007). Nesse processo, foi-se formando a consciência de si e, a seguir, a consciência de classe.

Em meio ao processo de acumulação do capital e de brutal exploração das forças de trabalho, os conflitos se tornavam mais agudos, impulsionando a luta por direitos. Diante de uma realidade perversa, movimentos dos trabalhadores e de suas organizações se fortaleciam. As greves, antes proibidas e criminalizadas, passaram a toleradas e, depois, legalizadas. A luta pelo voto universal mobilizava o campo da política. Intelectuais, partidos políticos, a Igreja demandavam por uma regulação apta a limitar a ação predatória do movimento do capital.

Criavam-se as condições para o nascimento de mecanismos legais de proteção aos trabalhadores que colocavam diques à ação trituradora do movimento do capital, contrapondo-se ao primado da autonomia das vontades. Um novo ramo do direito era gestado. Ainda que suas raízes estejam fincadas no século 
XIX, grosso modo, até a Primeira Guerra, 1914-1918, não se lhe reconheceu caráter autônomo (Biavaschi, 2007).

A Organização Internacional do Trabalho (OIT), que veio com o pacto de Versalhes, em 1919, foi marco decisivo para seu reconhecimento internacional. Frase inscrita na Constituição da OIT, “O trabalho não é mercadoria”, buscou solidificá-lo em âmbito internacional como um direito moderno e social (Krotochin, 1959). Situado na contramão de um liberalismo que não dava conta da Questão Social e acentuando a condição humana do trabalhador como tema central de seus fundamentos, o Direito do Trabalho marcou diferença ao unir o elemento humano, pessoal, ao social, coletivo, imbricando-os. Talvez nenhum outro ramo do direito se apresente com tal fisionomia. Não à toa, ele e as instituições aptas a dizê-lo têm sofrido duros golpes em tempos de regresso liberal (Biavaschi, 2016). Fenômeno profundamente imbricado na vida das relações sociais de cada país, sua gênese não pode ser compreendida apartada das lutas concretas e das circunstâncias históricas de cada sociedade (Biavaschi, 2007). No Brasil, as condições para seu nascimento como ramo autônomo do direito constituíram-se em meio ao seu processo de industrialização, na década de 1930. Essa década, é verdade, não inaugurou o reconhecimento da necessidade da legislação social, necessidade essa expressa em normas esparsas de proteção ao trabalho na República Velha e nas discussões dos deputados na Câmara Federal, ${ }^{4}$ basicamente em períodos de greve.

Antes da proclamação da República, no período pré-abolição, houve tentativa de o Estado coordenar o processo de integração de uma categoria de trabalhadores que se formava: os escravos em processo de alforria e os alforriados, negros libertos que, pela via dos pleitos judiciais, colocavam em debate temas relacionados com o direito de ir, a liberdade, a preservação da saúde, os direitos de constituir família, ter moradia e religião, receber educação, isto é, com a concretude de seus direitos (Chalhoub, 1990). Também alguns Códigos de Posturas Municipais, anteriores à Lei Áurea, adotaram regramentos para serviços de creados, porém de forma embrionária e bastante precária (Biavaschi, 2016, p.19-27).

\section{A Eva Vargas e os diveitos sociais do trabalho}

No Brasil de 1930, grande parte da população estava na zona rural. O proletariado urbano, de formação recente, ainda que tivesse acúmulo de reivindicações, não se apresentava com força orgânica capaz de impulsionar um processo de positivação das normas de proteção social de forma eficaz. O substrato material de suas lutas políticas não era igual àquele da Inglaterra do século XIX, da Grande indústria. Mesmo os movimentos grevistas de 1917 e 1920 não formaram essa base sólida. Nada surpreendente. Há poucas décadas se haviam rompido as amarras da escravidão. A dualidade senhor/escravo não estava superada. O trabalhador "livre" não se havia firmado como sujeito de direitos (Biavaschi, 2007). 
Até 1930 o país era essencialmente agrário. Durante a década de 1920, o produto agrícola representou, em média, $58 \%$ do PIB; a indústria, apenas $23 \%$, como se pode ler do Gráfico l:

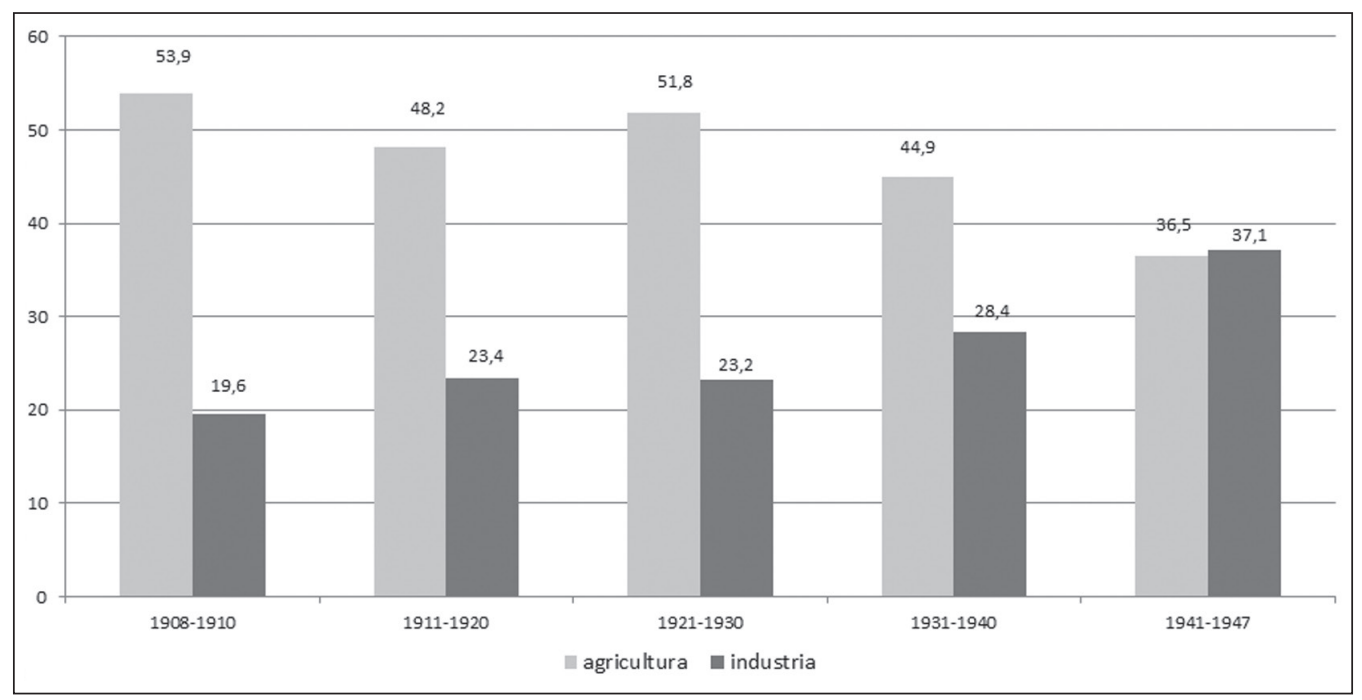

Fonte: Ipeadata. Elaboração: Memorial da Justiça do Trabalho do Rio Grande do Sul.

Gráfico l - Brasil: participação da agricultura e da indústria no PIB em \% (1908-1947)

A Aliança Liberal foi derrotada nas urnas, em pleito acusado de fraudulento. O que não era novidade diante do sistema sufragista da República Velha. Entre a derrota e a Revolução (Fontoura, 1958), Vargas vacilou sobre a opção armada. Porém, em célebre discurso "Rio Grande, de pé, pelo Brasil", justificaria essa opção diante da fraude eleitoral (Vargas, 1938, p.53-63). A Revolução de outubro triunfou.

O Governo Provisório iniciou em meio a uma profunda crise econômica. A criação do Ministério do Trabalho, Indústria e Comércio (MTIC), o "Ministério da Revolução", ${ }^{5}$ foi um de seus primeiros atos. Lindolfo Collor seria o primeiro ministro da pasta. Gaúcho, positivista, redigira o Manifesto que passou a integrar a plataforma da candidatura à Presidência da República (Fonseca, 1989), divulgada na Esplanada do Castelo, em 2 de janeiro de 1930. A partir de então, o Brasil passou a lutar pela superação das características que, até então, marcavam sua estrutura econômica, social e política: resquícios de uma ordem escravocrata, patriarcal e monocultora, herança dos tempos coloniais; sociedade eminentemente agrária; economia subordinada a um modelo primário exportador; operariado urbano esparso e não organizado; política "café com leite", ${ }^{6}$ com domínio dos proprietários rurais do eixo Minas/São Paulo; sufrágio não universal e não secreto, sem participação feminina; Questão Social tratada como questão de polícia (Vargas, 1938, p.15-54). 
Tratava-se de caminhada difícil e complexa de transformação capitalista envolvendo expansão econômica fundada em novas bases, numa dinâmica específica e própria do processo de constituição das condições materiais do capitalismo, de formação de suas classes (basicamente a burguesia industrial e o proletariado) e de construção dos aparelhos de Estado. O Estado passou a dirigir o processo de industrialização e a coordenar politicamente os interesses distintos que estavam em jogo (Biavaschi, 2007; 2016, p.19-27).

Essas questões, que desafiavam a Era Vargas, não poderiam ser equacionadas de forma descolada do contexto internacional. Mudanças significativas estavam em andamento. Em xeque o liberalismo econômico diante do solapamento da ordem liberal, a resposta da humanidade foi antiliberal, quer pela via democrática, quer de forma autoritária (Barbosa de Oliveira, 1998, p.3-19). No início do século XX a Revolução Russa de 1917 afirmava-se como experiência planificadora da economia. Outra experiência pioneira foi a dos escandinavos que, compreendendo a importância da coordenação racionalizadora das medidas de intervenção do Estado (Myrdal, 1962), consolidavam seus universalistas Estados de Bem-Estar, ${ }^{7}$ com sistema de proteção social garantido institucionalmente (Biavaschi, 2007). Reformas das estruturas capitalistas foram levadas a efeito pelos Estados Unidos, com o New Deal do presidente Roosevelt e, também, ainda que com marcadas diferenças, pela Itália fascista e, a partir de 1933, pela Alemanha nazista (Biavaschi, 2007). O tema da construção do Direito do Trabalho insere-se nessa complexidade.

Vargas, dialogando com essas experiências, adotou políticas de regulação extramercado, inclusive para o mundo do trabalho. Muitos decretos do Governo Provisório asseguraram direitos aos trabalhadores, sem distinção de sexo. Às mulheres era reconhecido o status de cidadãs. Poderiam votar. O Brasil foi o quarto país do hemisfério ocidental a instituir o voto feminino. Poderiam trabalhar e propor suas reclamações trabalhistas quando direitos trabalhistas thes eram sonegados sem dependerem da outorga do marido. O Decreto n.21.417, de 17 de maio de 1932, assegurou-lhes direitos, como: salário igual para trabalho de igual valor e normas de proteção à maternidade. Tiveram definida a jornada de trabalho e, quando instituída a carteira de trabalho, também lhes foi assegurado obtê-la independentemente da aquiescência do marido. Da mesma forma, o decreto que instituiu as Juntas de Conciliação e Julgamento em novembro de 1932 assegurou-lhes o direito de apresentarem suas reclamações indepentendemente da outorga ou da assistência dos maridos. Nesse processo, as mulheres conquistavam direitos decorrentes da prestação do trabalho por conta alheia, não eventual, subordinado e remunerado (Biavaschi, 2007).

\section{A CLT e a Justiça do Trabalbo}

No dia 10 de novembro de 2013 foi comemorado o $70^{\circ}$ aniversário da CLT, aprovada pelo Decreto-Lei n.5.432, de $1^{\circ}$ de maio de 1943, para viger em 10 de novembro daquele ano. Pensada no início da década de 1940, ela foi 
abrangente e ousada, como é exemplo o artigo $2^{\circ}, \mathfrak{S} 2^{\circ}$ que trata da solidariedade das empresas que compõem o grupo econômico, dentre outros institutos que permanecem atuais.

A história de sua construção está profundamente imbricada ao processo de criação e instalação da Justiça do Trabalho no Brasil. Sua vigência tem sido marcada por forte polêmica teórica. De um lado, certa corrente de pensamento apontando para sua "rigidez" incompatível com os "tempos modernos", no suposto de que o incremento da produtividade exige seja flexibilizada para que os bens produzidos no Brasil possam ser competitivos em nível mundial. De outro, expoentes do pensamento econômico heterodoxo argumentam ser equivocado atribuir à regulamentação do trabalho o motor da competitividade, defendendo que os direitos sociais não podem sucumbir frente à competição internacional dos mercados (Biavaschi, 2016).

Em 1932, para dar efetividade às normas de proteção aos trabalhadores, às mulheres e aos menores, foram criadas as Juntas de Conciliação e Julgamento. Instâncias administrativas e paritárias, eram compostas pelo presidente, escolhido pelo presidente da República dentre pessoas de notório saber jurídico, e pelos representantes classistas, dos empregadores e dos empregados, escolhidos pelo presidente da República a partir de listas encaminhadas pelos sindicatos e com mandato temporário (Biavaschi, 2007).

Em 1934, a Justiça do Trabalho foi introduzida no capítulo da organização econômica e social brasileira. Em 1935, Oliveira Viana, então consultor do MTIC, encaminhou à Câmara dos Deputados projeto de sua organização, elaborado no interior do MTIC. Seus princípios fundamentais eram, entre outros: composição paritária, identidade do juiz, processo oral, prova imediata, concentração dos atos processuais, instância única, gratuidade, execução das suas decisões, poder normativo. A proposta recebeu forte contestação liberal. Waldemar Ferreira, relator na Comissão de Constituição e Justiça, apontou sua suposta inconstitucionalidade por atribuir à Justiça do Trabalho "poderes legiferantes", sublinhando sua "inspiração fascista". Os princípios fundamentais da proposta eram, entre outros: composição paritária, identidade do juiz, processo oral, prova imediata, concentração dos atos processuais, instância única, gratuidade, execução das suas decisões, poder normativo. Retirada por Vargas, a proposta seria apresentada mais uma vez ao Parlamento, sendo igualmente resistida e retirada (Biavaschi, 2007; 2013).

A Constituição de 1937 definiu a Justiça do Trabalho como sendo um organismo especial e autônomo destinado a dirimir conflitos entre empregados e empregadores regulados pela legislação social. Com base nesses dispositivos constitucionais, em 2 de maio de 1939 ela foi criada por meio do Decreto-Lei n.1237, nascendo como nós a conhecemos até ser extinta a representação classista e ampliada sua competência pela Emenda Constitucional n.45. Em 1940, novo regulamento alterou alguns aspectos, prevendo, ainda, sua instalação oficial para $1^{\circ}$ de maio de 1941 . 
Portanto, a Justiça do Trabalho, prevista constitucionalmente em 1934, criada em 1939, regulamentada em 1940, foi oficialmente instalada em 1941. Em 1939, foram definidas suas atribuições e seus órgãos: as Juntas de Conciliação e Julgamento, os Conselhos Regionais do Trabalho e o Conselho Nacional do Trabalho, futuro Tribunal Superior do Trabalho, para, no ano seguinte, ser regulamentada, com previsão de ser instalada em $1^{\circ}$ de maio de 1941. Em 1946, com a estrutura pensada por Oliveira Viana, foi integrada ao Poder Judiciário.

Enquanto a década de 1930 marcou a pujança da produção normativa trabalhista, com momentos de relevância na Lei dos Dois Terços, no voto universal, nos direitos das mulheres e dos menores, na limitação da jornada, na extensão da estabilidade aos trabalhadores da indústria e do comércio, passando pela: criação das Juntas de Conciliação e Julgamento, elaboração da CLT e instituição da Justiça Especializada, no final da década de 1980 a Constituição de 1988 elevou os direitos dos trabalhadores à condição de direitos sociais fundamentais, completando o ciclo de constituição do arcabouço jurídico institucional trabalhista e de construção do Estado Social.

Nesse processo, tanto a Justiça do Trabalho quanto a CLT sofreram oposição ferrenha dos setores mais conservadores da sociedade brasileira, sendo ameaçadas aqui e ali em suas existências. Afinal, são pedras no sapato dos que querem eliminar os obstáculos ao livre trânsito de um capitalismo "sem peias".

\section{Segundo momento}

Nas décadas de 1980 e de 1990 a livre circulação da riqueza financeira para países garantidores de maior rentabilidade invadiu a gestão do setor produtivo, sobretudo nas grandes corporações, entrelaçando-se o capital produtivo ao fictício (Braga, 1997). No âmbito da estrutura produtiva, alteraram-se formas consolidadas de organização. As empresas passaram a deslocar parte dos processos de trabalho para prestadoras de serviço que atuam de forma dispersa e fragmentada, com motivações econômicas aparecendo no centro das iniciativas (Biavaschi; Teixeira, 2015). É importante ressaltar que tais mudanças aparecem inseridas em um conjunto de transformações em nível mundial, ainda que as especificidades de determinada região sejam relevantes para definir o raio de manobra dos Estados nacionais no estabelecimento de suas políticas. Os países desenvolvidos relegaram aos menos desenvolvidos a condição de exportadores de matéria-prima ou de produtores de bens de baixo valor agregado. Por outro lado, em um contexto de grande concorrência internacional, a gestão do processo de produção se concentrou nas mãos de grandes grupos econômicos, acirrando-se a disputa dos periféricos por recursos submetidos, em regra, às diretrizes mundiais de gestão.

Como uma das expressões desse movimento, nos anos 1990 a terceirização se intensificou no conjunto dos países da América Latina, processo que se compreende no bojo das modificações dos padrões de produção e de organização do trabalho que nos países centrais se fizeram sentir depois do período 
de dinamismo econômico e social que caracterizou os trinta anos gloriosos do pós-guerra.

No Brasil, com a abertura econômica e financeira nos anos 1990 e em um cenário de concorrência, as empresas introduziram mudanças nos processos de organização do trabalho e gestão (Teixeira; Coelho, 2013), adotando a terceirização como estratégia de redução de custos e busca de maiores lucros.

Vivem-se tempos de abalo das instituições republicanas e de derrocada dos direitos do trabalho em escala universal, aliás, um dos efeitos deletérios do capitalismo contemporâneo. Os embates se intensificam à ação dos que insistem em destruir as conquistas sociais incorporadas pela Constituição Federal de 1988 fundamentadas nos princípios da dignidade humana e do valor social do trabalho. São frequentes afirmações veiculadas pela grande imprensa de que desenvolvimento econômico e redução do desemprego são inviáveis nos marcos da Constituição de 1988. A tese é a de que é necessária a aprovação de propostas legislativas que aprofundem as políticas de ajuste fiscal adotem teto de gasto do governo, desvinculem os gastos com as receitas para saúde e educação, desvinculem os benefícios da Previdência do salário mínimo, elevem a idade para aposentadoria, aprofundem as privatizações, entre outras. Além disso, intensifica-se a defesa de propostas regressivas em tramitação no Parlamento, tais como: a que amplia a terceirização para quaisquer atividades econômicas, via contratação de empresas especializadas; a que flexibiliza o conceito de trabalho escravo; a que adota a supremacia do "negociado sobre o legislado", em que o encontro das vontades "iguais" produz a norma que rege as relações sociais do trabalho, cabendo à lei a condição de fonte supletiva.

Quanto à terceirização, importantes estudos na área econômica a têm analisado. Por um lado, economistas e estudiosos do mainstream apontam-na como via de incremento à produtividade, à competitividade e à geração de postos de trabalho. Por outro, textos e pesquisas com outra visão de mundo concluem não haver evidência teórica ou empírica de que essa forma de contratar contribua para aumentar a produtividade e a competitividade, mas, sim, para o aprofundamento das iniquidades e da precariedade no trabalho (Santos; Biavaschi, 2014, p.19-35).

Estudos em desenvolvimento no eixo "Terceirização" do Projeto Temático: "Contradições do Trabalho no Brasil Atual. Formalização, precariedade, terceirização e regulação", que compreendem essa forma de contratar como uma das expressões do movimento do capitalismo contemporâneo hegemonizado pelos interesses das finanças, a têm apontado como estratégia adotada, em regra, pelas empresas para reduzirem o custo do trabalho, com impactos nocivos na vida dos trabalhadores e de suas organizações. Pesquisas acadêmicas têm evidenciado que os trabalhadores terceirizados são os mais sujeitos a acidentes de trabalho e que, nos setores de confecções ${ }^{8}{ }^{8}$ sobretudo, têm sido submetidos a regimes análogos ao da escravidão. ${ }^{9}$ 
O PLC 03/2015, em tramitação no Senado Federal, corresponde a um retrocesso em relação ao entendimento da Súmula 331 do Tribunal Superior do Trabalho (TST). Retirando os limites que essa Súmula coloca para o uso da terceirização na atividade fim da tomadora, o projeto a estende para quaisquer atividades desde que contratados trabalhadores via empresas especializadas. Por outro lado, permite a quarteirização ao dispor sobre a contratação de serviços por pessoas jurídicas ou cooperativas. Nesse sentido, acaso aprovada, provocará substancial reforma trabalhista em prejuízo às conquistas incorporadas ao patrimônio jurídico dos trabalhadores, permitindo, no limite, a existência de empresas sem empregados e trabalhadores sem direitos, pois todos poderão ser contratados por meio de ajustes de natureza civil ou comercial. Já quanto à proposta que introduz o "negociado com supremacia sobre o legislado" nega, por essa via, o caráter de disputa próprio da relação capital e trabalho, apostando que o encontro das vontades "livres" define as normas que regem as relações de emprego. Por certo, está em pauta o redesenho da tela de proteção social conquistada a partir de duras lutas pelos trabalhadores deste país de mil e tantas misérias.

\section{Terceiro momento: considerações finais}

Desde a defesa da tese de doutoramento que, em parte, fundamenta este texto, houve mudanças visíveis no Brasil e no mundo, sobretudo a partir da crise mundial de 2008, gerada pela overdose de um capitalismo sem peias. Apesar dessas evidências, os direitos sociais continuam a sucumbir à força bruta e às políticas de ajuste impostas pelos organismos emprestadores de dinheiro, cujos efeitos deletérios são visíveis, inclusive nos países centrais. No Brasil, certa corrente de pensamento insiste na "quebra" da alegada rigidez da CLT para que sejamos competitivos e para que a produtividade aumente, apontando para a negociação coletiva como espaço normativo privilegiado, ao argumento renovado de que é nas brechas do mercado que o Estado deve regular.

Tanto a proposta da supremacia do que é negociado sobre o que é legislado quanto a que regulamenta a terceirização - na Câmara dos Deputados, PL 4.330/04, e, no Senado, PLC 30/2015 - insistem na adoção de caminhos que já se mostraram desastrosos no final do século XIX e início do século XX, os quais sucumbiram à evidência de que os interesses abstratos do dinheiro atuam como verdadeira avalanche quando não há diques suficientes para detê-los. Ao invés de se buscar superar as heranças herdadas do Brasil colônia retratadas na epígrafe que abre este texto, busca-se receituário cujos efeitos destrutivos já se mostraram insustentáveis ao se atribuir ao mercado a direção dos destinos dos homens, levando-os a sucumbir ao assalto de moinhos satânicos, em referência à metáfora de Polanyi (1980). 
Notas

1 Em referência a Guimarães Rosa, Grande sertão: veredas.

2 Sobre a dialética hegeliana do senhor e do escravo, ver Kojève (2002, p.157-87).

3 Banda de rock-reggae nascida na Baixada Fluminense fruto do trabalho da Fase/RJ.

4 Ver: Annaes da Câmara dos Deputados. Sessões de 2 a 31 de julho de 1917, v.III, RJ, Imprensa Nacional, 1918; Annaes da Câmara. Sessões de 1 a 16 de julho de 1918, v.IV, RJ, Imprensa Nacional, 1919.

5 Decreto n.19.433, de 26 de novembro de 1930.

6 Um presidente do Partido Republicano Paulista era sucedido por outro do Partido Republicano Mineiro.

7 Sobre os modelos de Welfare State, ver Esping-Andersen (1990).

8 Foram noticiados casos de trabalho análogo ao de escravo em duas grandes marcas da indústria têxtil: Zara e Le Lis Blanc. Disponível em: < http://cidadeverde.com/ noticias/190315/terceirizacao-aumentara-casos-semelhantes-a-trabalho-escravo-diz-procurador>; <http://www.cartacapital.com.br/economia/zara-e-autuada-por-nao-cumprir-acordo-para-acabar-com-trabalho-escravo-8409.html, http://reporterbrasil. org.br/2013/07/roupas-da-le-lis-blanc-sao-fabricadas-com-escravidao/>; e <http:// economia.uol.com.br/noticias/redacao/2013/08/21/loja-le-lis-blanc-tera-de-pagar-indenizacao-de-r-1-mi-por-trabalho-escravo.htm $>$.

9 Disponível em: <http://www.prtl.mpt.gov.br/informe-se/noticias-do-mpt-rj/204-pl-da-terceirizacao-prejudica-combate-ao-trabalho-escravo-e-cota-para-pessoas-com-deficiencia >; <http://cidadeverde.com/noticias/190315/terceirizacao-aumentara-casos-semelhantes-a-trabalho-escravo-diz-procurador>. Acesso em: 16 set. 2015.

\section{Referências}

BARBOSA DE OLIVEIRA, C. A. Industrialização, desenvolvimento e trabalho no pós-guerra. In: OLIVEIRA, M. A. de. (Org.) Economia \& trabalho: textos básicos. Campinas: Unicamp, IE, 1998. p.3-19.

O processo de industrialização: do capitalismo originário ao atrasado. São Paulo: Unesp; Campinas: Unicamp, 2003.

BARBOSA DE OLIVEIRA, C. A.; HENRIQUES, W. Cadernos do CESIT. Texto para discussão n.03. Determinantes da Pobreza no Brasil. Campinas, julho de 1990. Publicado originalmente em: São Paulo em Perspectiva, Revista da Fundação Seade, v.4, n.2, abr./jun. 1990.

BELLUZZO, L. G. O capital e suas metamorfoses. São Paulo: Unesp, 2013.

BIAVASCHI, M. B. O Direito do Trabalho no Brasil - 1930-1942: a construção do sujeito de direitos trabalhistas. São Paulo: LTr, 2007.

A construção e os fundamentos do Direito do Trabalho no Brasil. Revista do Advogado, ano XXXIII, n.121, p.178-85, nov. 2013.

. A construção das Normas de Proteção Social ao Trabalho e seus fundamentos:

Uma homenagem à Professora Doutora Gabriela Neves Delgado. In: VIANA, M. T.; 
ROCHA, C. J. da. (Coord.) Como aplicar a CLT à luz da Constituição: alternativas para os que militam no foro trabalhista. São Paulo: LTr, 2016. p.19-27.

BIAVASCHI, M. B.; MORETTO, A.; DROPPA, A. Terceirização e seus impactos sobre as relações de trabalho em pequenos negócios e sobre a morosidade na execução trabalhista. Revista O social em questão, ano XVIII, n.34, 2015.

BIAVASCHI, M. B.; TEIXEIRA, M. O. A terceirização e seu dinâmico processo de regulamentação no Brasil: limites e possibilidades. Revista da ABET, v.14, n.1, jan.-jun. 2015.

BRAGA, J. C. Financeirização global. In: FIORI, J. L. Poder e dinheiro: uma economia política da globalização. Petrópolis: Vozes, 1997.

CHALOUB, S. Visões da liberdade. São Paulo: Cia. das Letras, 1990.

COSTA, E. V. da. Da monarquia à República. 7.ed. São Paulo: Editora Unesp, 1999.

ESPING-ANDERSEN, G. The three worlds of welfare capitalism. Princeton: Princeton University, 1990.

FONSECA, P. C. D. Vargas: o capitalismo em construção - 1906-1954. São Paulo: Brasiliense, 1989.

FONTOURA, J. N. da. Memórias: da Aliança Liberal à Revolução de 1930. 2v. Prefácio de Francisco Campos. Porto Alegre: Globo, 1958.

FREYRE, G. Casa-grande \& Senzala. 25.ed. Rio de Janeiro: José Olympio, 1987.

GOMES, A. de C. Burguesia e trabalho. Rio de Janeiro: Campus, 1979.

KOJÈVE, A. Introdução à leitura de Hegel. Rio de Janeiro: Contraponto/Eduerj, 2002.

KROTOSCHIN, E. Tendências actuales en el Derecho del Trabajo. Buenos Aires: Ediciones Jurídicas Europa-America, 1959.

MARX, K. Contribuição para a crítica da economia politica. Lisboa: Estampa, 1977.

MYRDAL, G. O Estado do futuro. Rio de Janeiro: Zahar, 1962.

MORAIS FILHO, E. de. Introdução ao Direito do Trabalho. São Paulo: LTr, 1971.

POLANYI, K. A grande transformação. 3.ed. Rio de Janeiro: Campus, 1980.

SANTOS, A. L. dos; BIAVASCHI, M. B. A terceirização no contexto da reconfiguração do capitalismo contemporâneo: a dinâmica da construção da Súmula $n^{0} 331$ do TST. Revista do Tribunal Superior do Trabalho. Ano 80, n.3, jul.-set. 2014. p. 19-35.

TEIXEIRA, M. O.; COELHO, E. Que tempos são estes, em que é necessário defender o óbvio? Sindicato dos Químicos de São Paulo, 2013. Mimeo.

VARGAS, G. A nova politica do Brasil. Rio de Janeiro: José Olympio, 1938. v.1, 19301931. 
RESUMO - O artigo aborda o processo de construção do Direito do Trabalho, ramo autônomo do direito fundamentado em princípios que são sua razão de ser, cuja gênese está localizada na Grande indústria do século XIX, em tempos de capitalismo constituído. A seguir, dando ênfase às especificidades socioeconômicas do Brasil de 1930, discute essa construção no país pari passu ao seu processo de industrialização. Nessa caminhada, passa pelas normas de proteção ao trabalho, pela criação das Juntas de Conciliação e Julgamento em 1932, pela Justiça do Trabalho e pela Consolidação das Leis do Trabalho, a CLT, em 1943, caminhada não linear que se completa com a Constituição de 1988, que eleva os direitos dos trabalhadores à condição de direitos sociais fundamentais. Em um segundo momento, traz elementos para a discussão sobre o processo de desconstrução dessa tela de proteção social, em tempos de capitalismo globalizado e hegemonizado pelos interesses das finanças, com foco na terceirização, chegando às considerações finais.

PALAVRAS-CHAVE: Direito do Trabalho, Justiça do Trabalho, Regras trabalhistas, Terceirização.

ABSTRACT - The essay discusses the process of building Labor Law, an autonomous branch of Law anchored on basic principles that are its raison d'être and whose genesis is in the Great Industry of the $19^{\text {th }}$ Century. This is followed by some considerations on this process in Brazil in the 1930s, pari passu to the country's industrialization, emphasizing certain Brazilian socio-economic specificities. To this end, the essay examines the development of some labor rules, the creation of the "Juntas de Conciliação e Julgamento" (Councils of Conciliation and Judgment), Labor Justice and the Consolidation of Labor Laws (CLT), in 1943, in a non-linear process that continued until the Federal Constitution of 1988, in which workers' rights are elevated to the condition of basic social rights. In a second moment, the article highlights certain elements in order to discuss the deconstruction of the social protection net as one of the impacts of today's globalized capitalism, focusing on the regulatory process of outsourcing in Brazil. To conclude, some final considerations are made.

KEYWORDS: Labor law, Labor justice, Labor rules, Outsourcing.

Magda Barros Biavaschi é desembargadora aposentada do TRT4, doutora e pós-doutora em Economia Social do Trabalho pelo Instituto de Economia da Unicamp, pesquisadora no Centro de Estudos Sindicais e de Economia do Trabalho (Cesit/IE-Unicamp) e professora convidada em cursos de Pós-Graduação do Instituto de Economia e do Instituto de Filosofia e Ciências Humanas da Unicamp. @-magdabia@terra.com.br

Recebido em 5.7.2016 e aceito em 19.7.2016.

I Instituto de Economia, Universidade Estadual de Campinas, Campinas/São Paulo, Brasil. 
